\title{
G2 Y LA RETERRITORIALIZACIÓN EN UNA MATRIA MIGRANTE: IGIABA SCEGO Y GUILLERMINA MEKUY
}

\author{
POR \\ Selena Nobile \\ Università della Calabria, Italia
}

“La migrazione è l'espressione di una realtà altra all'interno della volontà del sistema capitalistico, che, diffuso ormai a livello planetario, contiene all'interno di se stesso zone di alterità assoluta, si chiamino esse 'sottosviluppo', 'paesi in via di sviluppo', 'emergenti', o 'terzo mondo', o 'sud del mondo"'1 (Ponzio Petrilli 149). Es por lo tanto, el emblema del contacto, de la interconexión entre el norte y el sur del mundo. Además, la condición diaspórica representa, con palabras di Gnisci, la calidad primordial del destino de los humanos, un valor, un dolor, una condición del existir y una aventura que da origen a la humanidad y que les permite producir discursos e imaginarios infinitos (Creolizzare, 77 énfasis mío).

Hoy en día este fenómeno es cada vez más evidente, y desvela con fuerza la alteridad haciendo fracasar el discurso monológico imperante. La presencia del migrante demuestra que no existe una representación universal del mundo. Pone de manifiesto cómo las relaciones que el sujeto migrante establece se fundan en una diferencia no-indiferente (Ponzio, "Introduzione", La differenza). De hecho, son relaciones rizomáticas que conectan la identidad con la otredad, entregándoles la misma dignidad. El fenómeno de la migración en países como Italia y España, es un fenómeno bastante reciente y presenta características muy parecidas. Por muchos años han sido países de emigración, y, sólo en los últimos veinte, treinta años se han convertido en países receptores de migrantes. ${ }^{2}$

1 La migración es la expresión de una realidad otra dentro de la voluntad del sistema capitalista, que, extendido ya a nivel planetario, contiene dentro de si mismo zonas de alteridad absoluta, llámense 'subdesarrollo', 'países en vías de desarrollo', 'emergentes', o ‘tercer mundo' o 'sur del mundo'.

2 Se calcula, por ejemplo, que a partir de su unificación unos treinta millones de italianos han dejado ese país. Al mismo tiempo, como afirman Sami Naïr y Juan Goytisolo: "los españoles [durante el siglo xx] por razones a la vez socioeconómicas y políticas, huyen de España. Esta hemorragia se prolonga hasta principios de los años setenta" (108). En cambio, hoy en día, "los flujos de entradas hacia ambos países están en constante aumento; la proporción de emigrantes del continente africano se incrementa con regularidad; las salidas se han reducido considerablemente" (Naïr 116-117). 
Todo esto lleva consigo muchas implicaciones, como, por ejemplo, la necesidad de redefinir nuevos espacios de encuentros. De hecho, el retraso con el que este fenómeno ha empezado a manifestarse en estos países, les ofrece a España y a Italia la posibilidad de elaborar un discurso nuevo, dialógico, teniendo a su disposición, como modelo de referencia, a la vez en positivo y a la vez en negativo, la experiencia adquirida por los demás países europeos que han tenido que enfrentarse ya con estas cuestiones.

Sin duda, un espacio de encuentro privilegiado es el de la literatura migrante. ${ }^{3} \mathrm{La}$ literatura es el lugar de la acogida, de la hospitalidad dada y recibida, de la hibridación y de la osmosis recíproca. En este sentido se hace vocera de la migración y puede ser un medio para elaborar un discurso nuevo que se ocupe de las cuestiones ligadas a la poscolonialidad y al neocolonialismo, superando todos los perjuicios, deconstruyendo la hegemonía y el dominio occidentalista que siguen elaborando modelos jerarquizados. Naciendo en un territorio fronterizo, la literatura migrante presenta fenómenos de contaminación lingüística, de superposiciones de identidades polimorfas, por lo tanto, es un producto híbrido, "menor" en la acepción de Deleuze y Guattari. Es una literatura que desvela las hipocresías y las contradicciones del mundo contemporáneo. La existencia misma de estas literaturas nos demuestra que las categorías críticas utilizadas hasta ahora son demasiado restrictivas. La oposición, que definiría casi dicotómicas, entre literatura nacional por un lado y poscolonial por el otro, no tiene en cuenta las zonas de contactos, la hibridación y la mutua influencia que existen, y que ha existido desde siempre entre todos los sistemas literarios. De hecho, es cada vez más necesario "undermine the monolithic nature of the postcolonial debate" (Ponzanesi XIV) y desmontar el concepto de literatura nacional. ${ }^{4}$ Para realizar este proyecto es imprescindible elaborar teorías nuevas aptas a descolonizar la actitud occidentalista.

En una entrevista el escritor somalí Nuruddin Farah, ${ }^{5}$ hablando de su escritura y de todas las escrituras migrantes, afirmó que no es importante el idioma en el que un escritor

3 Con el término escritura migrante me refiero a esos autores que de las periferias se han mudado al centro y han elegido como su lengua literaria el idioma de los países de acogida, idioma que no siempre coincide con el colonial y que muchas veces ha sido aprendido como segunda lengua con todas las implicaciones lingüísticas que esto conlleva.

4 ¿Cuál es el confín entre lo que se considera literatura nacional y lo que suele definirse poscolonial? ¿Cómo hay que definir esa literatura elaborada por autores procedentes de países que han sufrido el colonialismo pero que han vivido toda su vida en otro país? ¿Sus escritos entran dentro del canon de la literatura nacional o de la poscolonial o son otras cosas? ¿Y si es nacional, a qué nación nos estamos refiriendo: a la del país de procedencia o de residencia? Además ¿es posible aplicar el concepto de literatura nacional en algunos países africanos donde ya la categoría misma de nación puede resultar demasiado rígida? ¿Es diferente la escritura de quien utiliza la lengua colonizadora desde su país con respeto a los que la utilizan desde los de acogida? ¿Y cómo hay que estudiar esos escritos redactados en una lengua de expresión que no coincide con la lengua colonial del país de procedencia?

5 "Generazioni a confronto. I passaggi della letteratura somala". I saperi dell'Africa in movimento: letteratura e testimonianze. Festival della letteratura. Mantúa, 6 sept. 2008.

Revista Iberoamericana, Vol. LXXX, Núms. 248-249, Julio-Diciembre 2014, 987-1010 
se expresa sino que el valor literario de su obra reside en el espacio literario que ocupa. Un territorio desde el cual puede presentar un punto de vista excéntrico, exotópico, que nos ayuda a construir una imagen pluriversal del mundo contemporáneo. Parafraseando a Nuruddin Farah, se puede afirmar que este espacio traspasa los confines nacionales y lingüísticos y nos deja entrar, nos hospeda, en un territorio nuevo donde al patriarcado, a la identidad, a la jerarquía, se sustituye el matriarcado, la otredad por excelencia.

En el presente estudio me centraré en el análisis de las literaturas migrantes elaboradas por dos escritoras procedentes de las ex-colonias africanas en Italia y en España, dos países donde la escritura nómada es un territorio bastante inexplorado ya que es un fenómeno bastante reciente. Concretamente, me centraré en la escritura migrante de Igiaba Scego, de origen somalí, y Guillermina Mekuy, originaria de Guinea Ecuatorial, dos de la G2. ${ }^{6}$ Escritoras que dominan perfectamente el idioma por haber nacido en Italia, en el caso de Igiaba Scego, o por haberse trasladado a España a los seis años, en el caso de Guillermina Mekuy, ${ }^{7}$ y que viven en las dos culturas entrecruzándolas.

En ambos países podemos distinguir dos momentos fundamentales en la génesis de esta literatura. En una primera fase, es posible detectar a esos autores que, recurriendo al uso de la primera persona, y, en algunos casos a la ayuda de periodistas y escritores ${ }^{8}$ han contado su viaje a España y a Italia. Han contado de la ilusión/desilusión, del racismo del que han sido víctimas, de la dificultad a integrarse en el país de acogida. En Italia, destacamos, por ejemplo a la antropóloga y ensayista camerunesa Geneviève Makaping autora del libro Traiettorie di sguardi e se gli altri foste voi?, al tunecino Salah Methnani autor de Immigrato escrito en colaboración con el escritor Mario Fortunato, o a la brasileña Fernanda Farias de Alburquerque autora de la autobiografía Princesa, obra editada por Maurizio Iannelli. Por lo que concierne España podemos pensar en la novela Dormir al Raso del marroquí Mohamed El Gheryb y de Pascual Moreno Torregrosa, en la novela autobiográfica La niña de la calle de la marroquí Kaoutar Haik y Virtu Morón, en la novela Diario de un ilegal del marroquí Nini Rachid, obra escrita en árabe y luego traducida al castellano que cuenta cómo viven los indocumentados en España. Muy interesantes resultan también los ensayos de los guineoecuatorianos Antolín-Elá Elá Asama Viaje en patera ida y vuelta y Remei Sipi Mayo Inmigración y

\footnotetext{
Autodefinición que se han dado los migrantes de segunda generación.

7 Últimamente, Guillermina Mekuy se ha trasladado a Malabo donde dirige la Biblioteca Nacional inaugurada en junio de 2009.

8 Las obras escritas a cuatro manos pueden presentar problemas de autoría. ¿Hasta que punto, de hecho, el coautor ha intervenido en el texto? Los autores, en buena medida, son autores que no son hispanófonos o italófonos de forma que es posible que el coautor, haya intervenido en el texto insertando cambios lingüísticos considerables. En el caso de la novela Princesa, por ejemplo, el mismo coautor ha reconocido que esta obra es el resultado de una revisión de apuntes escritos en una lengua híbrida, producto de la fusión entre el italiano hablado, el brasileño y el sardo.
}

Revista Iberoamericana, Vol. LXXX, Núms. 248-249, Julio-Diciembre 2014, 987-1010 ISSN 0034-9631 (Impreso) 
género. El caso de Guinea Ecuatorial, ensayo este último que se ocupa de la condición de las mujeres migrantes procedentes de su país.

En una segunda fase, aún manteniendo, en buena medida, el uso de la primera persona, han empezado a hablar de su vivir la frontera alejándose cada vez más, de la mera urgencia de denunciar la alienación y el extrañamiento que se siente en las sociedades de acogida. En sus obras, ya no se limitan a contar de la migración vista como viaje hacia El Dorado, sino, se enfrentan con la cuestión de la alteridad/identidad, de la integración vista como posibilidad y al mismo tiempo como pérdida de algo. En muchos casos, ya no se sienten extraños en las metrópolis, por el contrario, describen su estar dentro y fuera reivindicando su derecho de ciudadanía en el mundo en el que viven. En fin, se miden también con la elección de la lengua de escritura y con las implicaciones ideológicas que conlleva.

En los últimos años la crítica y el mundo editorial, ${ }^{9}$ parecen haberse dado cuenta de esta realidad. Han empezado a instituirse premios literarios, ${ }^{10}$ y han nacido revistas especializadas. ${ }^{11}$ Sin embargo, si por lo que concierne Italia es más fácil encontrar datos estadísticas que nos den muestra de estos fenómenos, ya que han sido elaboradas bases de datos que recogen informaciones bibliográficas detalladas acerca de los escritores migrantes italófonos, ${ }^{12}$ más complicado resulta elaborary catalogar estos datos en España. ${ }^{13}$

Entre los disponibles, y analizando sólo los relativos a los escritores de origen africano, se puede afirmar que en Italia, entre los escritores migrantes africanos, sólo una parte procede de las ex -colonias. De hecho, la mayoría es originaria de Marruecos, que es el primer país del cual, a finales de los años sesenta, han empezado a llegar los

9 En Italia hay editoriales especializadas en la publicación de estos autores, como por ejemplo Besa, Sinnos, Eks\&Tra, Donzelli, edizioni e/o assolo, Kumá. Por lo que concierne España, me refiero al proyecto editorial Inmenso Estrecho e Inmenso Estrecho II llevado al cabo por la editorial Kailas, antología de textos que se enfrentan con el tema de la migración escritos por autores españoles y migrantes, $o$, a las publicaciones de la editorial Sial/Casa de África, El Cobre, etc...

${ }_{10}$ En Italia, un ejemplo de premio está representado por el concurso literario Eks\&Tra que ha llegado ya a la XIII edición, en España por el concurso Cuéntame tu diversidad que ha llegado a la séptima edición.

11 En Italia, las revistas especializadas en estas temáticas tienen casi todas su página web. Destacamos las siguientes: Il Caffè http://www.archivioimmigrazione.org/caffe.htm; Sagarana: http://www.sagarana. net/; Kumá: http://www.disp.let.uniroma1.it/kuma/kuma.html; El Ghibli: http://www.el-ghibli.provincia. bologna.it/; Letteranza: http://www.letterranza.org/

${ }_{12}$ En la universidad La Sapienza de Roma, por ejemplo, bajo la dirección del profesor Gnisci, se ha realizado una base de datos digitalizados que puede consultarse en la página web: http://www.disp.let. uniroma1.it/basili2001.

${ }^{13}$ Es posible encontrar informaciones bibliográficas en las siguientes páginas web: http://www. angelfire.com/sk2/guineaecuatorial/; http://www.casafrica.es/; http://www.asodegue.org/; http://www. culturafricana.com/; http://www.ariadna-rc.com/numero25/sahara/sahara033.htm; http://www.umdraiga. com/bibliografia/biblio_poesias.htm

Revista Iberoamericana, Vol. LXXX, Núms. 248-249, Julio-Diciembre 2014, 987-1010 
primeros migrantes. ${ }^{14}$ Queda patente, por lo tanto, que la mayoría de estos escritores han aprendido el italiano como segunda y quizás como tercera lengua. En España, donde la recopilación de los datos es más empírica, se puede decir que, sin tener en cuenta los escritores procedentes de Hispanoamérica, la mayoría de los autores migrantes procede de las ex-colonias africanas ${ }^{15}$ (Guinea Ecuatorial, Marruecos, Sahara Occidental), con la excepción de autores, como Agnès Agboton originaria de Benín, de Inongo Vi-Makomé, originario de Camerún. Un elemento muy interesante es que se están escribiendo obras migrantes también en los demás idiomas oficiales de España como en el caso de las marroquíes Najat El Hachmi, ganadora en 2008 del Premio Ramon Llull, y de Laila Karrouch que han escrito novelas en catalán.

El hecho de que, por lo que concierne España, la mayoría de los que he definido escritores migrantes procedan de las ex-colonias africanas tiene sus implicaciones ideológicas y lingüísticas. La mayoría de ellos ha aprendido el castellano antes de llegar a España, y de hecho este idioma sigue siendo su "botín colonial". Sin embargo, el elemento más importante es que poseen una dimensión comprometida muy fuerte hacia su país de origen. En muchos casos la imposibilidad de volver a Guinea Ecuatorial, o al Sahara Occidental se transforma, respectivamente, en una denuncia patente y vibrante del régimen que manda en ese país, como en el primer caso, o en una en contra de la ocupación marroquí como en el segundo.

Otro elemento que España e Italia comparten, y que puede ser útil a la hora de acercarse a estas literaturas, es que en estos dos países no ha habido una verdadera reflexión poscolonial. De hecho, todavía no han resuelto la cuestión de su colonización de África. Por lo que concierne a Italia, la cultura oficial muy raramente se ha ocupado de su presencia en Libia, Eritrea, Etiopia y Somalia. Lo mismo pasa en España, país en el que muy raramente los historiadores han escrito acerca del movimiento africanista/ colonialista que empujó a la conquista de África, en el siglo xIx, en particular de Marruecos y, del fortalecimiento de la presencia española en Guinea Ecuatorial que ya había empezado en los siglos XVIII y xIx. Las razones de este olvido culpable son varias y distintas, sin embargo, en buena medida, tienen que ver con el papel marginal que ambos países desarrollaban en el panorama del imperialismo europeo a finales del siglo xIX y al principio del siglo xx, y con unas contradicciones muy fuertes que había dentro de cada país.

${ }_{14}$ Datos actualizados el 20 de septiembre de 2008 y disponibles en la página web: http://www.disp.let. uniroma1.it/basili2001/Bollettino\%20di\%20sintesi\%20della\%20Banca\%20dati\%20Basili\%202008.pdf.

15 Entre todos destacamos a los marroquíes Saïd El Kadaoui, Mohamed Chakor, Montserrat Abumalham, a los saharauis Bahia Mahmud Awah, Mohamed Salem Abdelfatah conocido con el seudónimo de Ebnu, Limam Boicha, Chejan Mahmud, y, a los guineoecuatorianos Francisco Zamora Loboch, Donato Ndongo-Bidyogo, Justo Bolekia Boleká, María Nsue Angüe, Remei Sipi Mayo y Antolín-Elá Elá Asama.

Revista Iberoamericana, Vol. LXXX, Núms. 248-249, Julio-Diciembre 2014, 987-1010 
Italia, al final del siglo xIx, acababa de unificarse. Su retraso en configurarse como un estado unitario la dejaba fuera de la división estratégica de África que el resto de las potencias europeas estaba llevando al cabo. Su unificación se producía bajo la guía de una élite cultural, política y económica que había elaborado todo un discurso ideológico en torno al mito de Roma, de su imperio, y que presentaba a Dante como el primer teórico de la unidad de Italia. En realidad esta idea de Italia era el resultado de un discurso artificial inventado ad hoc para justificar la conquista del sur del país: "The notion of a 'reemergence' of the Italian national spirit is rather artificial. Aside from its geography, the only other time was unified was under Roman colonization" (Verdicchio 195). De hecho, cuando se habla de unificación de Italia, sería más correcto hablar de su "piemontización". En este proceso, el sur y los sureños estaban representados como "feminized, inferior, uncivilized and ineffective" (197). Si analizamos con atención estos estereotipos, nos damos cuenta de que son los mismos a los que las potencias europeas recurrirán para justificar su política imperial en África. No es por casualidad que Said, para explicar el fenómeno del imperialismo, utilice las mismas categorías, como hegemonía y dominio, elaboradas por Gramsci para analizar La questione meridionale y las cuestiones ligadas al Risorgimento italiano. Italia, por lo tanto, es un país que, antes de representarse como una potencia colonial, nace de un proceso colonizador: "the history of the Italian south is one of the colonization, where colonialism was the unspoken agenda when Italy was 'united' by Piedmontese forces in the 1960s" (191).

Sólo si se tiene en cuenta este punto de partida, es posible acercarse al proceso de colonización italiana, y, entender, sin por eso justificar, el porque de la falta, en Italia, de la construcción de un discurso poscolonial, excluyendo los estudios de Angelo Del Boca y de otros historiadores. De eso depende el hecho de que en ese país falta la toma de conciencia que su colonialismo ha sido tanto violento y destructor como el de las demás potencias europeas. Quizás incluso peor ya que, a pesar de su negativa, los italianos recurrieron al uso de las armas químicas para derrotar la resistencia etíope:

Nell'Italia del dopoguerra, infatti, nessuno pensa lontanamente di processare Badoglio e gli altri generali per il loro crimini commessi in Africa (Del Boca 118). Per venti mesi Graziani mise l'Etiopia a ferro e fuoco nell'inutile tentativo di piegare una resistenza che coinvolgeva la quasi totalità delle popolazioni dell'impero. Gli etiopici non lo ricordano soltanto per le tre giornate del febbraio 1937, quando, dopo aver subìto un attentato, autorizzò inauditi massacri nella città di Addis Abeba, ma per l'uso sistematico dell'iprite e del fosgene durante i rastrellamenti dei partigiani, per la fucilazione di migliaia di indovini e cantastorie (rei soltanto di aver annunciato nelle piazze la fine imminente dell'occupazione italiana), per la creazione dei letali campi di concentramento [...], per lo sterminio dei 449 preti e diaconi [...], per la deportazione

Revista Iberoamericana, Vol. LXXX, Núms. 248-249, Julio-Diciembre 2014, 987-1010 
in Italia dell'aristocrazia etiópica e la liquidazione física di tutti i giovani in possesso di un titolo di studio. $(124-125)^{16}$

De hecho, en el imaginario colectivo Italia "still percives itself more as a colonized country than as a colonizer" (Ponzanesi 105) y sigue en pie el mito que "il colonialismo italiano è diverso, più umano, più liberale, più tollerante"17 (del Boca VI).

Tanto como Italia, se puede decir que también España, a partir de la segunda mitad del siglo XIX, a causa de la perdida de casi todas las colonias ultramarinas, desarrollaba un papel bastante marginal en el panorama de las potencias mundiales. La situación había ido empeorando después de 1898, con la perdida de Cuba, Puerto Rico y las Filipinas. De hecho, si hasta ese momento:

España se [había concentrado] en la explotación de sus colonias americanas, y [había mantenido] en segundo termino sus intereses africanos (Nerín 15), [después de esa fecha] si algo quedó claro al final era que tan sólo en África, en Marruecos o en el golfo de Guinea, era posible consolidar posesiones y posiciones (Fradera i Barceló 10), [para] recomponer el quebrantado prestigio militar español(10). [África representaba] el espacio donde el espejismo de una colonización de nuevo tipo podía concretarse después de la nueva derrota de 1898, aunque al final aquel sueño gestado en el corazón del nexo constituido por los militares, políticos e intereses económicos que formaban la trama del estado liberal en España acabase engendrando la pesadilla del africanismo militar y de una Guinea de la copra y el cacao demasiada cercana a la lúcida y desesperada percepción conradiana. (10)

Si la Italia fascista justificaba la creación de su imperio haciendo recurso al mito del Imperio Romano, la España franquista fundó su discurso colonialista en la retórica hispanotropicalista, o sea, en las:

cinco características que supuestamente diferenciarían al colonialismo español en África del resto de las políticas coloniales: la innata vocación africana de los españoles, la

${ }_{16}$ En la Italia de la posguerra, de hecho, a nadie ni se le pasa por la cabeza procesar a Badoglio y a los demás generales por sus crímenes cometidos en África (Del Boca 118). Por veinte meses Graziani metió Etiopia a cuchillo y fuego en el intento inútil de derrotar una resistencia que envolvía la casi totalidad de las poblaciones del imperio. Los etíopes no se acuerdan de él sólo por los tres días de febrero de 1937, cuando, después de un atentado, autorizó masacres inauditas en la ciudad de Addis Abeba, sino también por el uso sistemático del gas mostaza y del fosgeno durante los rastreos de los partisanos, por el fusilamiento de miles de clarividentes y griot (culpables sólo de haber anunciado en las plazas la conclusión inminente de la ocupación italiana), por la creación de campos letales de concentración [...], por el exterminio de los 449 curas y diáconos [...], por la deportación a Italia de la aristocracia etíope y la liquidación física de todos los jóvenes que poseían títulos de estudio (124-125).

17 el colonialismo italiano es diferente, más humano, más liberal, más tolerante.

Revista Iberoamericana, Vol. LXXX, Núms. 248-249, Julio-Diciembre 2014, 987-1010 ISSN 0034-9631 (Impreso) 
tendencia misionera de la nación española, la ausencia total de actitudes racistas, y la difusión del mestizaje como consecuencia de este supuesto antirracismo genuinamente hispano. (Nerín 12)

Se puede decir que la postura de ambos países frente al colonialismo es bastante parecida, ya que, han ido representándose como fuerzas civilizadoras y con una innata vocación africanista, intentando auto-absolverse de sus responsabilidades, incluso en los años de la descolonización, y abandonando en un olvido culpable este pasado.

Los autores migrantes están llevando adelante una labor muy importante para la recuperación de esta memoria compartida y están abriendo el paso para dar a conocer estos temas olvidados. En su novela Regina di fiori e di perle Gabriella Ghermandi, autora de origen etíope, intenta reanudar el hilo de la memoria que une la historia de Italia con la de Etiopia. La protagonista Mahlet, casi sin quererlo, recopila, como una moderna azmari (cuentacuento que en África Occidental sería definido griot, o en el mundo árabe halaiqui), los cuentos de testigos directos que han vivido durante el colonialismo italiano, y, utiliza la oralidad para dar a conocer estas historias. Ella, una mujer, un sujeto menorizado que, por conocer ambas culturas, por haber sido educada en ambos países, por haber estudiado en el país que un tiempo había colonizado al suyo, sustituyéndose al hombre, (el azmari es un hombre), tiene la misión de contar escribiendo: "quando sarai grande scriverai la mia storia, la storia di quegli anni e la porterai nel paese degli italiani, per non dare loro la possibilità di scordare" $(57){ }^{18}$ Contará de: "i bombardamenti. I gas. Il sibilo delle bombe che cadevano al suolo e si spaccavano lasciando fuoriuscire quella nube che incendiava i polmoni da dentro"19 (28); de los amores prohibidos entre italianos y etíopes de cómo estaba permitido: “ andare con le donne di qui", ${ }^{20}$ pero tratándolas sólo como prostitutas ya que no podían: "amarle, avere figli con loro, sognare una famiglia. Se fai una cosa del genere loro applicano il decreto [...] l'ordine di rimpatrio e una condanna a cinque anni di reclusione"21 (44); de los arbegnà, guerrilleros, guidados por las mujeres:

Kebedech Seyoum era incinta [...]. Era incinta di quattro mesi, quando il marito, Aberrà Kassa, venne ammazzato. [...] Senza versare una lacrima ripiegò la lettera, e andò da Shileshy: 'Prendo il comando degli uomini di mio marito', disse, quindi ci convocò

18 "Cuando seas mayor escribirás mi historia, la historia de esos años y la llevarás al país de los italianos, para no darles la posibilidad de olvidarse".

19 "Los bombardeos. Los gases. El silbido de las bombas que caían al suelo y se rompían dejando salir esa nube que quemaba los pulmones desde dentro".

20 "Acostarse con las mujeres de aquí".

${ }^{21}$ Amarlas, tener hijos con ellas, soñar con una familia. Si haces una cosa de este tipo, ellos aplican el decreto $[\ldots]$ el orden de repatriación y una condena a cinco años de prisión.

Revista Iberoamericana, Vol. LXXX, Núms. 248-249, Julio-Diciembre 2014, 987-1010 
tutti. 'Noi continueremo a combattere', disse. Credetemi, mai, neppure un giorno... ma che dico, neppure per un momento gli uomini dell'armata hanno visto semplicemente una donna incinta. Lei è il nostro capo. $(187)^{22}$

En el caso de España, con referencia a su colonización de Guinea Ecuatorial, la atención de los escritores procedentes de este país se centra en particular en la presencia de los misioneros católicos, y en cómo su labor "moralizadora", que tenía el objetivo de imponer la moral católica, produjo fragmentación y contrastes dentro de las sociedades en las que se impuso la conversión. El intento de cambiar los hábitos sexuales, considerados escándalos, aún sin conocer realmente cómo se estructuraban las relaciones sexuales entre hombres y mujeres (Nerín 62), era una manera para controlar a estas tribus. El control del cuerpo es un medio para controlar el cerebro de los individuos (pensemos por ejemplo en el control del cuerpo ejercido, también en las sociedades occidentales, para someter a las mujeres, y a cómo este modelo fue reproducido durante el imperialismo). No hay que olvidar que los mismos misioneros aplicaron una doble moral. Si por un lado prohibían la poligamia entre los negros, permitían en concubinato entre los blancos y las mujeres negras (Nerín). En casi todas las obras está representado el contraste entre los que aceptan la imposición del catolicismo y, por medio de la religión, y del modus vivendi occidental y los que la rechazan para defender la sobrevivencia de sus tradiciones. Muy ejemplar en este sentido es lo que escribe María Nsue Angüe:

Ahora llega el blanco y os dice que ya no es hacia abajo sino hacia arriba a donde tendréis que partir, y os lo creéis [] ¿cómo sabéis que podréis entrar en el terreno sagrado de los blancos si aquí en la tierra no os dejan entrar en sus casa? (126). Parece ser que de repente ha pensado en bautizarse $y$, sin decir nada a nadie, ha estado yendo todas las tardes a la misión de los blancos para aprender la doctrina cristiana y, después de estudiar el catecismo y sabérselo, el cura blanco le ha dicho que si quiere ser bautizado ha de abandonar a tres de sus mujeres y quedarse sólo con una (116-117). Maldije a aquel hombre blanco porque hacía desgraciada a una familia y hacía desgraciados a unos niños, exponiéndolos a quedar sin madre. (118)

Esta fractura social está simbolizada también en el personaje que ha sido educado en las dos culturas, que ha tenido la posibilidad de irse a Europa, donde ha adquirido la mentalidad de los europeos y que, volviendo a su país de origen, ha rechazado su pasado prefiriendo el modelo europeo:

22 "Kebedech Seyoun estaba embarazada [...]. Estaba embarazada de cuatro meses, cuando el marido Aberrà Kassa, fue matado. [...] Sin llorar dobló la carta, y se fue donde estaba Shileshy: 'Tomo el mando de los hombres de mi marido', dijo, entonces nos convocó a todos. 'Nosotros seguiremos el combate', dijo. Creedme, nunca, ni por un solo día... qué digo, ni por un momento solo los hombres de la armada han visto en ella simplemente una mujer embarazada. Ella es nuestro jefe".

Revista Iberoamericana, Vol. LXXX, Núms. 248-249, Julio-Diciembre 2014, 987-1010 
Nfumbá'a, el africano de hoy, hombre del mañana, tras estar dos lluvias en Europa dejó su tradición encerrada entre los libros; dejó allí su personalidad y sus creencias africanas, y el ser sin continente regresó a su pueblo con un disfraz de europeo pero sin el europeo dentro: con una máscara de Europa pero sin su rostro en ella. Medio blanco, medio negro. (107)

Es evidente la referencia a Fanon y a su obra Peau noire, masques blancs, en la que analiza las relaciones de poder y de dominio que se establecen entre el colonizado y el colonizador. El colonizado termina por utilizar la lengua del colonizador, y con ésa por hacer suyos sus valores, sin poseer su rostro o sea, perdiendo su peculiaridad. Por lo tanto, es un hombre disfrazado que ha perdido su identidad y que vive a la sombra de lo que nunca podrá llegar a ser.

Reflexionar sobre el pasado de migración que ha caracterizado la historia de España y de Italia y también sobre el colonial, salir de ese proceso autorreferencial de absolución y de olvido significa tener otra actitud frente a la presencia del migrante y a su: “domanda di chi non trova posto nella totalità, nell'ordine dell'identico: di chi non può essere assimilato nella dialettica interna alla identità del capitale: domanda, che per la sua assoluta alterità, non rientra nel piano preordinato di una dialettica monologica, ma espone al rischio della dialettica dialogica"23 (Ponzio y Petrilli 151).

Si los ejemplos hasta aquí propuestos tienen como eje de referencia la necesidad de reanudar un pasado común, de denunciar las violencias, la destrucción de una civilización, la explotación económica de estos países, el proyecto que proponen Igiaba Scego y Guillermina Mekuy, autoras ya definidas G2, mira hacia el futuro partiendo del pasado y obrando en el presente. Hace referencia a la interculturalidad a una hibridación que de facto se ha producido, ellas mismas son el resultado de ésta. Su proyecto es un proyecto de reterritorialización en un espacio matriarcal abierto y complejo en el que no existen jerarquías y relaciones de poder dirigidas de forma unidireccional. Presentan su visión del mundo alternativa, otra, desde un "territorio" doblemente excéntrico por ser mujeres y por ser "migrantes" procedentes de África.

Como escritoras, ya por el hecho de ser mujeres, se colocan en una posición incómoda y revolucionaria porque subvierten el ser ontológico, identificado con lo masculino, haciendo derrumbar sus certidumbres y desvelando la otredad. Lo femenino se autoafirma por medio de la escritura (manera para salir del silencio impuesto) autolegitimando su derecho a manifestar su alteridad. Además, por ser mujeres de origen africano, deconstruyen los estereotipos por medio de los que la mujer africana ha sido

23 "Petición de quien no encuentra emplazamiento en la totalidad, en el orden de lo idéntico: de quien no puede ser asimilado en la dialéctica interior a la identidad del capital: petición, que por su absoluta alteridad, no entra en el plano pre-ordenado de una dialéctica monológica, sino se expone al riesgo de una dialéctica dialógica".

Revista Iberoamericana, Vol. LXXX, Núms. 248-249, Julio-Diciembre 2014, 987-1010 
representada por el hombre occidental y, al mismo tiempo, por la escritura femenina occidental.

La mujer africana, desde siempre ha sido representada como un objeto débil que debía ser protegido por el hombre blanco, o sea, parafraseando la retórica colonialista, debía ser dominado por él, y por la iglesia, la que se presentaba artificialmente como la defensora de la emancipación de la mujer. Además le han entregado una imagen exótica y sensual: "The representation of the local women-through photography, postcards, and literary accounts-as Veneri Neri, beautiful, docile, but mostly sexually available, corroborated the most important aspect of the rhetoric of empire (124). [Native women] are an extraordinary, wonderful object to lust after and to consume, but nothing more" (Del Boca en Ponzanesi 125). Autoras como Igiaba Scego y Guillermina Mekuy, a esta estética de lo bello, fundada en una deshumanización que transforma la mujer en un objeto que se puede poseer y dominar, oponen una estética de la fealdad, metáfora de la subjectivización del ser femenino. Sus personajes femeninos nunca presentan rasgos exóticos ni se caracterizan por su beldad. Por el contrario, en Igiaba Scego son incluso feos ya que la femineidad que describe es independiente de la belleza física.

Esta estética de la fealdad es funcional para deconstruir también el discurso monolítico, elaborados por las mujeres occidentales, para representar a la mujer del tercer mundo, en oposición al discurso plural y vitalista con el que ellas mismas se han representado. Chandra Talpade Mohanty afirma que, el feminismo occidentalista universalizando el concepto de "mujer del tercer mundo", ha reproducido un modelo hegemónico parecido al modelo patriarcal colonialista. Igiaba Scego y Guillermina Mekuy, en cambio, al elaborar su discurso doblemente excéntrico se están insertando en este debate demostrando la pluriversalidad de los mundos femeninos procedentes de África. Apropiándose de la palabra escrita, están reivindicando, como mujeres, su propio espacio en el mundo y en la sociedad en la que viven. En su dimensión fronteriza, enlazan sus raíces africanas y europeas, las que se sobreponen influenciándose de forma recíproca. Esta relación rizomática propone, por lo tanto, un discurso feminista nuevo que se aleja de la tradición occidentalista y que, introduciendo una dialéctica nueva, mina las certidumbres y los puntos de arranque del "heterogéneo" feminismo occidental. Proponen una emancipación otra, "menor", que pasa por la deconstrucción de la imagen de África y por una reapropiación alternativa del propio cuerpo. De esta forma reterritorializan su escritura en una nueva matria, en un espacio desde el cual pueden autoafirmar su multiplicidad.

Igiaba Scego, en Oltre Babilonia elaborando también una denuncia del colonialismo, una dimensión comprometida que no encontramos en la obra de Guillermina Mekuy, deconstruye la imagen de África por medio de la doble violación de una mujer y de un hombre, los futuros padres del único personaje masculino que tendrá cabida en la novela, por parte de unos militares italianos. La violación perpetrada sobre el cuerpo de

Revista Iberoamericana, Vol. LXXX, Núms. 248-249, Julio-Diciembre 2014, 987-1010 
un hombre sirve precisamente para deconstruir el mito machista del europeo colonizador y consecuentemente toda la propaganda edificada entorno a este mito.

En Guillermina Mekuy, África se identifica con un espacio atemporal, idealizado. Es un edén perdido, porque en la memoria de María Fátima, por ejemplo, es el sitio de la infancia de cuando era feliz. Su deconstrucción de la imagen de África se realiza presentándola precisamente como el continente que dio origen a todo, como el centro del mundo. De hecho, África, a diferencia de cómo podría ser vista desde las metrópolis del centro, no es el lugar olvidado por Dios, el último, el más pobre, por el contrario, desde su perspectiva excéntrica, representada incluso por mujeres blancas españolas que han preferido Guinea Ecuatorial a su país de origen, África es

la Tierra del Origen, en el lugar donde primeramente puso su dedo Dios para alumbrar la vida. Una tierra más cercana a la Divinidad que ninguna porque no había sido manchada por la suciedad de la civilización (96), [y que] no era el último lugar del mundo, sino el primero, la tierra donde Dios posó su mirada para crear al hombre. (Las tres virgenes 200)

Guillermina Mekuy se enfrenta con el tema de la liberación de la mujer en sus dos novelas. Sin embrago realiza este proyecto claramente sobre todo en la novela Las tres vírgenes de Santo Tomás donde pone de manifiesto cómo la emancipación pasa por el mantenimiento de la virginidad. Esto no significa que las tres mujeres que protagonizan la obra (María Inmaculada, María Fátima y María Lourdes), renuncien a su sexualidad como, en cambio, el padre Ondó Mikó habría querido imponerles. Por el contrario, cada una vivirá su propia sexualidad sin someterse nunca al poder machista, y cada una lo hará eligiendo libremente su propio destino. Guillermina Mekuy nos propone tres modelos de mujeres libres complementarias entre sí. María Inmaculada liberará su ser femenino en la dimensión de la homosexualidad. Seguirá siendo virgen y al mismo tiempo vivirá el deseo, la pasión y el amor con su pareja. Ella se ha rebelado al proyecto de sus padres de casarla con un hombre elegido por ellos y de: "ser una esclava seglar para el Señor, [de ser] una virgen mental que pondría su cuerpo para reproducir y traer al mundo apóstoles o nuevas siervas de Dios y a la que no le estaría permitido ningún goce" (144-145). Frente a esta situación ha tomado libremente su decisión: a la virginidad mental ha preferido una real: "todavía soy virgen y, además, creo que lo seré siempre... y sin ninguna dificultad" (142), porque ha encontrado su matria compartiendo su vida con otra mujer. Su hermana menor María Lourdes, aún convirtiéndose en la Madre Superiora del Convento, conocerá la dimensión humana y sensible del placer junto con la divina: "yo he compartido durante estos últimos meses la soledad del padre Andrew, sus tentaciones, sus dudas. Yo he compartido el aspecto humano del amor. Y el divino, porque probablemente no son muy distintos, y aunque

Revista Iberoamericana, Vol. LXXX, Núms. 248-249, Julio-Diciembre 2014, 987-1010 
sin faltar a mis votos he conocido el deseo y su satisfacción, la ternura y la culpa, la felicidad y el dolor" (220-221).

En fin, encontramos a María Fátima, protagonista principal de la obra por ser la voz narradora de la misma. María Fátima, es la que:

puede ofrecer [su] cuerpo a la lujuria, emular todas las mujeres del mundo que se han prostituido, [pero es al mismo tiempo una sacerdotisa] será deseada acariciada, lamida, sojuzgada, pero nadie penetrará en [ella], ni aun cuando esté en medio de una orgía de hombres que [la]quieran poseer y a los que les dará todo menos una cosa: el húmedo tesoro de [su] virginidad. (110)

Vivirá el deseo, el placer, la lujuria sin conceder nunca su virginidad. De esta forma obtendrá el control sobre el hombre y nunca será sometida a su poder. Hay que tener en cuenta que una mirada demasiado dicotómica, puede resultar inadecuada para interpretar el proceso de concienciación propuesto por la autora. En el imaginario feminista occidental ,esta elección puede parecer ilógica, en algunos casos la re-proposición de otra forma de limitación a la libertad femenina. A mi parecer, en cambio, Guillermina Mekuy consigue construir un personaje capaz de fortalecerse disfrutando de la debilidad del ser masculino. De hecho, negando a todos los hombres el entregamiento de su virginidad consigue, controlar su deseo, su cuerpo y consiguientemente su cerebro. Concretamente reproduce en sus relaciones amorosas, subvirtiendo las relaciones de poder, el modelo de control del hombre sobre la mujer perpetrado por medio de una moral católica y sexista. Por lo tanto, apoderándose de su sexualidad se libera del poder machista haciendo derrumbar el modelo social patriarcal oponiéndole, entonces, otra matria. Dicho derrumbamiento está simbolizado por el mutismo del padre, mutismo que caracteriza los últimos años de su vida: "Tomás había entrado en el silencio, ese silencio de los que se saben perseguidos, aislados, incomprendidos. Sin voces interiores ni exteriores que le acompañaran, se había convertido en un náufrago esperando que alguien le lanzara un salvavidas" (241). Ondó Mikó o Santo Tomás se encierra en su mutismo al darse cuenta que, a pesar de todos sus intentos, sus rezos, sus hijas son mujeres libres, mujeres que han rechazado esa antítesis virgen/puta y se presentan como figuras de intersección, híbridas. De hecho, María Fátima se autodefine la "Virgen del placer" (244). Puede ser virgen y puta al mismo tiempo y puede ser todo lo que han decidido ser. En este sentido recuerda desde muy cerca la nueva concientización propuesta por las escritoras chicanas.

Si en Las tres vírgenes de Santo Tomás la autora construye un nuevo modelo de mujer, lo mismo no se puede afirmar en su primera novela El llanto de la perra. De hecho, en esta obra la protagonista Eldania no llega nunca a un espacio matriarcal propio, es como si se quedara en un limbo. La protagonista es una pícara moderna que vive toda su vida en busca de un amo que mande en su existencia a partir de la relación que

Revista Iberoamericana, Vol. LXXX, Núms. 248-249, Julio-Diciembre 2014, 987-1010 ISSN 0034-9631 (Impreso) 
establece con su madre. Una madre ausente de la que su hija será dependiente por toda la vida y con la que conseguirá restablecer una relación entre pares sólo en los últimos meses de vida de la madre. Será sometida también a su hermanastra Mercedes la que la introducirá al placer del sexo y por medio de esto la controlará. Y en fin será sometida a todos los hombres que encontrará a Sergio, a Dester. En este recorrido picaresco que presenta una estructura circular y atemporal, Eldania no consigue rescatarse, como de hecho no lo consigue nunca el pícaro, el que vive sólo con la ilusión de haberlo hecho: “¿Había vuelto al pasado o no había existido nunca el futuro? [...] Empecé a caminar, sin rumbo, con el libro apretado contra el pecho, sabiendo que, dentro de mí, me acompañaría siempre el llanto de la perra" (220).

La protagonista se queda en una dimensión circular sin salida y sin salvación, metáfora del eterno retorno. La imposibilidad de liberarse está simbolizada por el hecho de que ella, para legitimar su embarazo necesita un hombre que la quiera, como si ella no estuviese a la altura de darle amor a su hijo: "Si Lemos me penetra, si consumo el amor con él, habrá sido una penetración con verdadero amor y mi hijo será más fruto del amor que nunca" (155). Lo mismo se puede decir de Mercedes, la que sólo en apariencia parece ser una mujer libre artifice de su destino. Su lascivia, en cambio, no es una manifestación de emancipación. Al fin y al cabo es una mujer infeliz, alcoholizada que busca en el sexo fuera del matrimonio una salida de la violencia y de la soledad en la que es obligada a vivir a causa de un matrimonio impuesto por su padre, otro hombre dominador, para esconder su embarazo. Otro embarazo, entonces, que para cumplirse, necesita una legitimación masculina/patriarcal:

Sobre todo por complacer a papá. [...] Nos casamos y su educación y su corrección parecía que me iban a permitir salir del mejor modo posible de la situación. Sin embargo, mi negativa a tener relaciones tantas veces como él deseaba le hizo agresivo; en realidad descubrió su brutalidad. Empezó a pegarme, a maltratarme, a amenazarme del peor modo posible. Por miedo, tuvimos dos hijos más, aunque nadie puede asegurar que sean suyos. Yo empecé a beber más de lo normal y a escaparme y tener relaciones con distintos hombres. (80)

También en Igiaba Scego encontramos una doble excentricidad en la representación de la mujer, y en su emancipación. En la novela Rhoda, esta mujer obligada a dejar Somalia para escapar de la guerra civil, se traslada a Italia con su tía Barni y su hermana menor Aisha. En su país ha dejado toda su vida y no se conforma a vivir en Italia. Además, se enamora de una mujer que la rechaza. Este rechazo la hace caer en un barranco y determinará su perdición. Empezará a prostituirse y se liberará sólo cuando, al descubrir de haber contraído el Sida, con la ayuda de su familia y de Pino, un joven que está enamorado de ella, volverá a Mogadiscio donde morirá defendiendo su "honra". Rhoda, protagonista en ausencia, por estar muerta y por hablar desde la tumba donde

Revista Iberoamericana, Vol. LXXX, Núms. 248-249, Julio-Diciembre 2014, $987-1010$ 
está sepultada en Mogadiscio, se ha re-apoderado de su cuerpo antes de morir, a través del uso del hijaab, paradigma de la vuelta a los orígenes:

Non so se sono riuscita a rimediare alla mia vita di merda alla fine, ma so che ritornare a casa mia mi ha aiutato a guadagnare un minimo di autostima. [...] mi ha aiutato ad amare di più il mondo e una certa persona di nome Rhoda. [...] Questo mi ha aiutato a morire con dignità (189). Per la prima volta ero simile agli altri, o almeno mi confondevo bene tra la folla. La mia lunga túnica verde e il mio hijaab quasi non si contraddistinguevano fra le varie tuniche. ${ }^{24}(191)$

y a través del redescubrimiento de una nueva virginidad:

Forse se mi fossi fatta montare come una vacca in calore ora, chissá, sarei viva. Dopotutto ero una fica che aveva conosciuto una marea di cazzi diversi nella sua vita. [...] Potevo aggiungere qualche cazzo in più alla memoria ed essere viva forse. Però sarei stata infelice. In quei mesi in Somalia mi ero purificata, depurata, ripulita. In un certo senso ero tornata vergine. ${ }^{25}(203)$

Rhoda resemantiza la palabra virginidad que se transforma en virginidad del alma superando, tanto como hemos visto en Guillermina Mekuy, la dicotomía virgen/puta. La presencia de la sangre que sale lentamente del cuerpo de Rhoda es otro elemento de purificación y de liberación: "Il sangue usciva da me senza fretta, spietatamente [...] -Balil se mi vuoi bene sparami... ti prego... fallo per me! [...] Prese la mira. Mi guardò ancora una volta. Questa volta con amore"26 (204). Esta dimensión purificadora está presente también en la novela Oltre Babilonia. Zuhra hija de la diáspora somalí a Italia, violada cuando era niña pierde la vista de los colores. A medida que pasa el tiempo y con la ayuda de su psicóloga los recupera todos excepto uno: el rojo. Otro viaje, otra vuelta a África, esta vez a Túnez le permite emprender un viaje dentro de sí misma. Esta ciudad, que metafóricamente representa el entrecruce entre todos los sures del

24 "No sé si lo he conseguido, en fin, poner algún remedio a mi vida de mierda, pero sé que volver a mi casa me ha ayudado a obtener un mínimo de autoestima. [...] me ha ayudado a amar más al mundo y a una cierta persona de nombre Rhoda. [...] Esto me ha ayudado a morir con dignidad (189). Por primera vez era como todos los demás, o por lo menos me mezclaba bien entre el barullo. Mi larga túnica verde y mi hijaab casi no se distinguían entre las demás túnicas".

25 "Quizás, si me hubiese hecho montar como una vaca en calor ahora, quizás, estaría viva. Al fin y al cabo era un coño que había conocido una marea de carajos diferentes en toda su vida. [...] Habría podido añadir algún carajo más a mi memoria y, quizás ahora, estar viva. Sin embargo estaría infeliz. En esos meses en Somalia me había purificado, depurado, relimpiado. En un cierto sentido había vuelto a ser virgen".

26 "La sangre salía de mí sin prisa, sin piedad [...] -Balil si me quieres dispárame... por favor... ¡hazlo por mi! [...] Puso la puntería. Me miró otra vez. Esta vez con amor".

Revista Iberoamericana, Vol. LXXX, Núms. 248-249, Julio-Diciembre 2014, 987-1010 
mundo: el Mogadiscio destruido por dieciocho años de guerra civil, el Buenos Aires de la dictadura militar, la Roma de los barrios populares y multiétnicos, es el espacio donde se curan las heridas y las fracturas interiores. El lugar físico donde metafóricamente se encuentran las teorizaciones africanistas, posorientales y posoccidentales, en la acepción de Mignolo. Zuhra, de hecho, al reconciliarse con el espacio matriarcal, con el mutismo de su madre, que se traduce en su voz grabada en una cinta, será capaz de ver el rojo de su sangre menstrual: el color de la vida:

Non ho partorito. Ho solo espulso. Non ho nessun cordone. Non devo nascondere nulla. Dopo, da sveglia ho toccato la mia pancia, ho sfiorato anche la mia vagina. Mi sono sentita così leggera! Sono andata oltre Babilonia, capisci? Oltre tutto, in un posto dove la mia vagina è felice e innamorata (449). È rossa la sua stella. Un po' umida. Ma bella. Emana luce. Una stella mestruale che brilla solo per lei, infinita. Le forme si disperdono. La stella si allarga. Una costellazione. Dentro la costellazione, la sua storia di donna. E dentro la sua storia, quella di altre prima di lei e di altre dopo di lei. Le storie si intrecciano, a volte convergono, spesso si cercano. Tutte unite da un solo colore e da un affetto. [...] In un attimo la costellazione si dissolve leggera. Sfuma lasciando un alone di rosso intorno. E forse così l'amore a Roma? Una sfumatura di rosso ${ }^{27}$ (456)

La elaboración de una emancipación nueva pasa también por el recurso al tema de la homosexualidad y de la transexualidad. A través de la presentación de modelos sexuales híbridos Igiaba Scego y Guillermina Mekuy crean un espacio nuevo en el cual la mujer no cae bajo el domino del hombre:

-No puedo dar un paso sin tener un admirador detrás... En realidad, he tenido demasiados pretendientes pero, no sé..., a lo mejor es que me gustan las chicas. [...] No, en realidad el tema no lo tengo demasiado claro. He tenido historias, como sabes, pero nada con visos de permanencia. [...] No me veo formando una familia. [...] Me di cuenta de que, durante una gran parte de mi vida, me hubiera gustado ser como Selene. Con su independencia, su seguridad su fuerza. Ella jamás se habría dejado dominar por un hombre, jamás se habría convertido en una perra, una esclava de los demás (Mekuy, El llanto 214)

27 "No he parido. Sólo he expulsado. No tengo ningún cordón. No tengo que esconder nada. Después, una vez despierta he tocado mi vientre, he rozado mi vagina. ¡Me he sentido tan ligera! He ido más allá de Babilonia, ¿entiendes? Incluso en un sitio donde mi vagina está feliz y enamorada. (449). Su estrella es roja. Un poquito húmeda. Pero bella. Emana luz. Una estrella menstrual que brilla sólo por ella, infinita. Las formas se dispersan. La estrella se ensancha. Una constelación. Dentro de la constelación, su historia de mujer. Y dentro de su historia, la de otras antes de ella y después de ella. Sus historias se entrecruzan, unas veces convergen, a menudo se buscan. Todas juntadas por un color solo y por un afecto. [...] En un momento se disuelve ligera. Esfuma dejando un alón de rojo en torno. ¿Quizás es éste el amor en Roma? ¿Una esfumatura de rojo?” (456).

Revista Iberoamericana, Vol. LXXX, Núms. 248-249, Julio-Diciembre 2014, 987-1010 
Para [ella] el amor es diferente. No pued[e] vivir el amor, ni siquera relacionar[se] con un hombre (Las tres vírgenes de Santo Tomás 142).

Il personaggio del transessuale, [es] una figura alquanto ricorrente fra gli autori migranti. Il transessuale ha in sé la dualità e l'ambiguità tipica di questa letteratura: la sua specificità contesa fra uomo e donna, il suo essere a metà tra i due sessi, sono elementi comuni anche agli autori stranieri che scrivono in italiano e probabilmente questo personaggio permette loro di mantenere un certo distacco dall'esperienza migratoria, senza perdere però di vista il nucleo centrale della loro poetica, e cioè la ricerca di una nuova identità. ${ }^{28}$ (Comberiati 3 )

De hecho, en este espacio ambiguo elaboran una dimensión exotópica que desvela las fracturas determinadas por la condición diaspórica. En el relato "Dismatria” Angelique, una drag queen, de su posición fronteriza se hace vocera de la condición absurda en la que viven las mujeres de ese piso, desvelando sus neurosis y en fin liberándolas: "Tenere la roba in valigia, non vivere, castrati. Questo è assurdo! Ma non lo vedete che è assurdo? Vi meravigliate delle mie tette, credete che sia pazza, ma i pazzi siete voi [...] non vi rendete conto?"29 (Scego, "Dismatria" 19).

La ambigüedad sexual abre también al tema del doble, del doble entre madre/hija que se configura también como inter-étnico. En sus obras las hijas de la migración casi nunca consiguen establecer un contacto comunicativo con sus madres. El enfrentamiento, el contraste entre las dos es muy fuerte y muy doloroso. La figura del padre es evanescente y en algunos casos es totalmente ausente. Sólo la madre, por lo tanto, puede reanudar el hilo de la memoria ayudando a su hija a reconciliarse con un pasado que no conoce pero que es la fuente del dolor que lleva dentro de sí misma. Y lo puede hacer grabando en una cinta sus recuerdos para compartirlos con ella, (Queda patente que la grabación de las cintas es un homenaje a la tradición oral africana):

Anche a casa ne giravano parecchie di cassette. Ricevevamo dalla Somalia le parole di una donna dalla voce roca. Maryam Laamane non mi faceva mai sentire quelle cassette. Non voleva. [...] Ma [...] io origliavo. Mi ricordo che piangeva sempre, davanti a quelle cassette. [...]-Una volta figlia mia, mi hai chiesto se con papà era stato bello. Trattengo il fiato. -Non ti ho saputo rispondere. Non saprei nemmeno dirti bene come sia andata

28 "El personaje del transexual, es una figura bastante recurrente entre los autores migrantes. El transexual tiene en sí la dualidad y la ambigüedad típica de esta literatura: su especificidad contendida entre hombre y mujer, su estar a mitad entre los dos sexos, son elementos comunes también entre los autores extranjeros que escriben en italiano y probablemente este personaje les permite mantener una cierta distancia de la experiencia migrante, pero sin perder de vista el núcleo central de su poética, o sea, la búsqueda de una nueva identidad".

29 "Tener la ropa en una maleta, no vivir, castratos. ¡Esto es absurdo! ¿Pero no lo veis que es absurdo? Os maravillan mis tetas, creéis que estoy loca, pero los locos son vosotros [...] ¿No os dais cuenta de esto?”

Revista Iberoamericana, Vol. LXXX, Núms. 248-249, Julio-Diciembre 2014, $987-1010$ ISSN 0034-9631 (Impreso) 
la faccenda tra me e lui, a dir la verità. Però in queste cassette c'è una risposta. Una delle tante possibili. Una risposta? Un tentativo? Sto tremando. [...] -C'è papà qui dentro? Chiedo -Ci siamo noi. Disse Maryam Laamane. ${ }^{30}$ (Oltre Babilonia 450-451)

O, escribiendo una larga carta a su hija, que atraviesa toda la novela, para contarle las verdaderas razones por las que huyó de Buenos Aires durante la dictadura militar de Videla. Para confesarle que no es una refugiada, una opositora del régimen, como todos sus admiradores creen, sino una mujer débil que había silenciado su conciencia, que había cerrado los ojos mientras estaban destruyendo la juventud y el futuro de su país. O, puede cortar el cordón umbilical con un pasado idealizado que no puede volver abriendo las maletas y poniendo la ropa en un verdadero armario para, en fin, meter las raíces en la nueva matria:

-Voglio comprarmi casa, mamma. Voglio andare a vivere da sola. Voglio un armadio anche, e non più valige, mai più [...] Avevo rotto il patto dei dismatriati. Ero un paria ribelle [...] Eravamo dismatriate, orfane, sole. Il nostro abbraccio durò all'infinito. Poi $[\ldots]$ ci accorgemmo che intorno a noi c'erano rovine. Tutti avevano svuotato le valigie. Anch'io corsi a svuotare le mie valigie. E stranamente lo stesso fece mamma [...] c'erano cose strane. Un pacco di spaghetti, foto di monumenti di Roma [...], un po' di terra in un sacchetto [...] -Che significa?- Dicevano i nostri occhi. -Non mi volevo dimenticare di Roma- disse mamma [...] Ci guardammo tutti. Sorriso globale. Non lo sapevamo, ma avevamo un'altra matria. ("Dismatria": 19-21) 31 $^{31}$

Este doble madre/hija es también inter-étnico. Las madres o la tía Barni son somalíes, saben cuál es su identidad, las hijas o las sobrinas, en cambio, poseen una identidad pluriversal por ser hijas de la diáspora. Las madres han tenido que cortar sus

30 "También en casa había muchas cintas. Recibíamos de Somalias las palabras de una mujer con la voz roca. Maryam Laamane no me dejaba escuchar nunca esas cintas. No quería. [...] Pero [...] yo orillaba. Me acuerdo que lloraba siempre, delante de esas cintas. [...] -Una vez, hija mía, me has preguntado si con papá había sido bello. Retengo mi respiro. -No te supe contestar. A decirte la verdad, no sabría ni decirte qué tal fue la historia entre él y yo. Sin embargo en estas cintas hay una respuesta. Una de las posibles respuestas. ¿Una respuesta?, ¿Un intento? Estoy temblando. [...] -¿Está papá aquí, dentro? Pregunto. -Estamos nosotros. Dijo Maryam Laamane.

31 “-Quiero comprarme una casa, mamá. Quiero ir a vivir sola. Quiero un armario también, y nunca más maletas, nunca más... Había roto el pacto de los dismatriati. Era un paria rebelde [...] Éramos dismatriate, huérfanas, solas. Nuestro abrazo fue infinito. Luego [...] nos damos cuenta de que en nuestro alrededor había ruinas. Todos habían vaciado las maletas. Yo también fui a vaciar mis maletas. Y me extrañó que lo hizo también mi mamá [...] había cosas raras. Un paquete de espaguetti, fotos de los monumentos de Roma [...], un poquito de tierra en una bolsa [...]-¿Qué significa?-Decían nuestros ojos. -No quería olvidarme de Roma- dijo mi mamá [...] Nos miramos todos. Una sonrisa global. No lo sabíamos, pero teníamos otra matria".

Revista Iberoamericana, Vol. LXXX, Núms. 248-249, Julio-Diciembre 2014, 987-1010 
raíces porque han tenido que abandonar su país de origen y manifiestan esta fractura refugiándose en el alcohol, como en el caso de la madre de Zuhra, o en su manera de vivir la relación con la lengua de acogida y con la lengua nativa. La lengua de acogida es para ellas también el idioma colonial, el idioma impuesto por los italianos y representa todavía una herida abierta, una ruptura del yo, como se puede notar en la novela Rhoda donde la tía Barni representa el paradigma del sujeto diaspórico. Ella, aún conociendo el italiano por haberlo estudiado en las escuelas italianas de Mogadiscio en los años del colonialismo, una vez llegada a Roma, lo rechaza porque no consigue integrarse en una sociedad que no acepta su diversidad, pierde cada vez más fluidez y soltura terminando por adaptarse al estereotipo del inmigrado que no sabe expresarse en otro idioma que no sea el suyo:

Lo aveva rinnegato, semplicemente. A furia di sentirsi dire: 'Voi negri non sapete l'italiano!', Barni aveva finito per crederci. Dante, Ariosto e Leopardi l'abbandonarono e il loro posto fu preso da verbi scandalosamente sgrammaticati [...] E finì col diventare quello stereotipo di donna immigrata che la società (o meglio i media) voleva vedere in lei. Barni si arrese per indolenza, senza lottare, senza crederci veramente. ${ }^{32}(155-156)$

La lengua materna, en cambio, representa el lugar de la matria perdida: "Mamma mi parla nella nostra lingua madre. Un somalo nobile dove ogni vocale ha un senso. La nostra lingua madre. Spumosa, scostante, ardita. Nella bocca di mamma il somalo diventa miele"33 (Oltre Babilonia 443). Las hijas se sienten somalíes y al mismo tiempo italianas. Son conscientes de poseer una identidad múltiple en la que conviven distintas almas en un proceso de osmosis recíproca: “A Roma la gente corre sempre, a Mogadiscio la gente non corre mai. Io sono una via di mezzo tra Roma e Mogadiscio: cammino a passo sostenuto"34 ("Dismatria" 5). Al mismo tiempo, su identidad polifacética es vivida, en algunos casos, de forma conflictiva: "Quella domanda odiosa sulla mia identità del cazzo! Più somala? Più italiana? Forse 3/4 somala e 1/4 italiana? $\mathrm{O}$ forse è vero tutto il contrario? Non so rispondere! Non mi sono mai 'frazionata' prima d'ora, e poi a scuola ho sempre odiato le frazioni, erano antipatiche e inconcludenti (almeno

32 "Lo había renegado, simplemente. A fuerza de oír que le decían: 'Ustedes los negros no saben el italiano!', Barni terminó por creérselo. Dante, Ariosto e Leopardi la abandonaron y en su lugar aparecieron verbos escandalosamente incorrectos [...] Y terminó por transformarse en ese estereotipo de mujer inmigrada que la sociedad (o mejor dicho los medios de comunicación) quería ver en ella. Barni se rindió por indolencia, sin luchar, sin creérselo de verdad".

33 "Mamá me habla en nuestra lengua materna. Un somalí noble en el que cada vocal tiene sentido. Nuestra lengua madre. Espumosa, huraña, ardita. En boca de mi madre el somalí tiene sabor a miel".

34 "En Roma la gente corre siempre, en Mogadiscio la gente no corre nunca. Yo me sitúo en el medio entre Roma y Mogadiscio: camino con paso rápido".

Revista Iberoamericana, Vol. LXXX, Núms. 248-249, Julio-Diciembre 2014, 987-1010 
per la sottoscritta)"35 ("Salsicce" 28), y se refleja también en el babel lingüístico que reúne todas sus lenguas maternas. El somalí que es el idioma da la madre, idioma que no está dominado perfectamente sino que está mezclado con el italiano. Sin embargo es el cordón umbilical que las une a sus madres, las únicas huellas de su antepasado:

Mi chiedo se la lingua di mia madre possa farmi da madre. Se nelle nostre bocche il somalo suoni uguale. Come la parlo io questa nostra lingua madre? Sono brava come lei? Forse no, anzi sicuramente no. Non mi sembro all'altezza della mia Maryam Laamane. [...] Non mi sento una figlia ideale. Incespico incerta nel mio alfabeto confuso [...] Ogni suono è di fatto contaminato. Ma mi sforzo lo stesso di parlare con lei in quella lingua che ci unisce. In somalo ho trovato il conforto del suo utero. ${ }^{36}$ (Oltre Babilonia 443)

La madre cuando habla en somalí pare, es una madre que pare a una lengua madre. La hija, en cambio, cada vez que intenta hablar el somalí:

ogni volta, in ogni discorso, parola, sospiro, fa capolino l'altra madre. Quella che ha allattato Dante, Boccaccio, De Andrè e Alda Merini. L'italiano con cui sono cresciuta e che a tratti ho odiato, perchè mi faceva sentire straniera [...]. L'italiano che scrivo. Non saprei scegliere nessun'altra lingua per scrivere, per tirare fuori l'anima. ${ }^{37}(444-445)$

Su incapacidad de escribir en otro idioma que no sea el italiano, y el hecho de que su somalí hablado es una lengua contaminada, por tener sabor de cimiento y de periferia urbana, es percibida, en algunos casos, como una limitación y como un dolor. Quizás una incapacidad de llegar a la tan anhelada perfección matriarcal: "Io ancora me ne vergogno, però. Vorrei essere perfetta in ognuna delle due senza sbavature. Ma quando ne parlo una, l'altra spunta sfacciata senza essere invitata [...] Io non parlo, mischio"38 (445).

35 ¡Esa pregunta odiosa sobre mi maldita identidad! ¿Más somalí? ¿Más italiana? ¿Quizás tres cuartos somalí y un cuarto italiana? O quizás todo lo contrario. ¡No sé contestar! Nunca hasta ahora me he fraccionado, y además en el instituto odiaba las fracciones eran antipáticas e inconsistentes (por lo menos para mí).

${ }^{36}$ Me pregunto si la lengua de mi madre pueda hacerme de madre. Si en nuestras bocas el somalí suene igual. ¿Cómo la hablo yo esta lengua materna nuestra? ¿Soy capaz como ella? Quizás no, seguro que no. No estoy a la altura de mi Maryam Laamane. [...] No me siento una hija ideal. Tropiezo insegura con mi alfabeto confuso [...] Cada sonido de hecho está contaminado. De todas formas hago esfuerzos para hablar con ella en esa lengua que nos une. En somalí encontré consuelo en su útero.

${ }^{37}$ Sin embargo, cada vez, en cada discurso, palabra suspiro, vislumbra la otra lengua materna. La que amamantó a Dante, Boccaccio, De Andrè y Alda Merini. El italiano con el que crecí y que en algunos momento he odiado, porque me hacía sentir extranjera [...] El italiano en el que escribo. No sabría elegir ninguna otra lengua para escribir, para echar mi alma.

${ }^{38}$ Sin embargo yo todavía me avergüenzo. Querría ser perfecta en cada una de ellas sin imperfecciones. Sin embargo cuando hablo en una vislumbra la otra sin haber sido invitada [...] Yo no hablo, mezclo.

Revista Iberoamericana, Vol. LXXX, Núms. 248-249, Julio-Diciembre 2014, 987-1010 
En Guillermina Mekuy el doble madre/hija está presente a partir de su primera novela. En esta obra Eldania vive toda su vida en busca de su doble desaparecido cuando era sólo una niña: su madre Inés. Toda su vida es el resultado del trauma ligado a la desaparición de la madre. Eldania se refleja en Inés de forma incluso inconsciente cuando, aún sin saberlo, se enamora del hijo del hombre por amor del cual Inés lo abandonó todo incluso a su hija, la predilecta. Hombre que tanto como le había pasado a su madre la hará sufrir, reproduciendo un círculo infinito de eterno retorno del dolor.

En su segunda novela, el doble madre/hija, es como en Igiaga Scego, un doble también inter-étnico. Las tres hermanas son hijas de una pareja mixta, por lo tanto han vivido en el espacio cultural fronterizo entre Guinea Ecuatorial y España. El elemento original que subvierte el discurso monológico imperante reside en el hecho de que el elemento blanco está simbolizado por la mujer, por la madre. Sin embargo, ella es la depositaria de la memoria africana. Teresa ama África, ama su espacio maternal hecho de hechicerías, de rituales mágicos, de oralidad. Un patrimonio que se trasmite de forma matrilineal. Ella por amor de su país de acogida (Guinea Ecuatorial) se transforma en una hechicera blanca y, recurriendo a la magia africana, a sus fórmulas rituales orales, libera a su hija negra del control del padre. El elemento negro está representado por el padre, el que, en este proceso de subversión del discurso, encarna el ideal europeo, su etnocentrismo y su dominio ejercido controlando el cuerpo femenino. Él es un fanático del catolicismo que, metiéndose una "máscara blanca", rechaza su pasado sus tradiciones africanas para trasladarse a España y condenar a formas de cadenas perpetuas a sus hijas. Para la protagonista, cuyas raíces son una síntesis, una hibridación de las del padre y de la madre, su identidad pluriversal reside en su manera de ver:

las imágenes de un mundo en constante fusión. Ahora soy dueña, en mi interior de dos culturas, me pertenecen dos países, y tengo la enorme riqueza de dos lenguas, la española y el fang, que forman mi presente y mi pasado (Las tres vírgenes 192) Mis dos países, mi añorada Guinea, y España, mi encuentro con el sufrimiento pero también con la liberación. Yo soy una mezcla. (191)

En estas escritoras, la cuestión de la lengua nunca es neutral. Su lengua no es la lengua de la academia, como ya se ha visto en Igiaba Scego, es una lengua abierta al intercambio, contaminada, el reflejo y la representación más evidente de esta identidad mestiza. El somalí se enlaza con el italiano tanto como el fang se sobrepone al castellano. La lengua de la expresión literaria convive con la lengua materna, o sea, la lengua de la madre como en el caso de Igiaba Scego, o con la lengua de la tierra natal, de la matria, como en el caso de Guillermina Mekuy. En la novela Las tres vírgenes de Santo Tomás se puede destacar cómo ésta última celebra la convivencia entre los dos idiomas y lo notamos, en particular, cuando María Fátima reflexiona sobre su identidad mestiza enraizándola en la superposición osmótica de las dos lenguas:

Revista Iberoamericana, Vol. LXXX, Núms. 248-249, Julio-Diciembre 2014, 987-1010 ISSN 0034-9631 (Impreso) 
aunque amo Guinea con todo mi corazón, también amo al país en el que he crecido [...] Esa tierra que es la tierra de mi idioma, la tierra por la que también soy europea. Ese fang que suena a magia y a exotismo y que nunca dejamos de hablar entre nosotros. La lengua de mi etnia y la lengua de mi cultura, las lenguas de un país único en el mundo que comparte el idioma de Cervantes con millones de personas. (192)

Para concluir se puede decir que con su "lenguaje de las mujeres" Igiaba Scego y Guillermina Mekuy, respectivamente con su italofonia e hispanofonia, están creando un espacio en el que escritura (vista como espacio europeo) y oralidad (vista como memoria de sus orígenes africanos) están la una en frente de la otra estableciendo una comunicación dialógica. Como si las lenguas africanas perdidas, maternas, privadas de la grafía volviesen en un eco vibrante. Su lengua de escritura "contaminada" es una lengua en movimiento que las sintetiza todas y que crea una matria en constante migración.

\section{BiBLIOGRAFÍA}

Boca, Angelo del. L'Africa nella coscienza degli italiani. Roma/Bari: Laterza, 1992. Braidotti, Rosi. Trasposizioni sull'etica nomade. Roma: Luca Sossella, 2008.

Comberiati, Daniele. "Le molte voci del 'soggetto nomade"". <www.retididedalus.it/

Archivi/2007/marzo/LETTERATURE_MONDO/Letteratura_migrante.pdf >

Curti, Lidia. La voce dell'altra. Roma: Meltemi, 2006.

Deleuze, Gilles y Félix Guattari. Kafka. Por una literatura menor. México D.F.: Era, 1978. Mil plateux (capitalisme et schizophrenie). París: Les Editions de Minuit, 1980. Mil Mesetas (capitalismo e schizzofrenia). José Vásquez Pérez, trad. Valencia: Pre-Textos, 1997.

El Gheryb, Mohammed y Pasqual Moreno Torregrosa. Dormir al raso. Madrid: Vosa, 1994.

Elá Asama, Antolín-Elá. Viaje en patera ida y vuelta. Madrid: Antolín-Elá Elá Asama, 2006.

El Hachmi, Najat. Jo també sóc catalana. Barcelona: Columna, 2004. L'últim patriarca. Barcelona: Planeta, 2008.

El último patriarca. María Prats Rosa, trad. Barcelona: Planeta, 2008.

Farah, Nuruddin. "Generazioni a Confronto. I Passagi della letteratura somala. panel:

I superi dell'africa in movimento: letteratura e testimonionze. Festival della Letteratura. Montúa, 6 sept. 2008. <http://www.nimedia.it/elabora/materiale/ MN_B_02_NuruddiniFarah.mp3>.

Farias de Alburquerque, Fernanda y Maurizio Jannelli. Princesa. Milano: EST Marco Tropea, 1997.

Revista Iberoamericana, Vol. LXXX, Núms. 248-249, Julio-Diciembre 2014, 987-1010 
Fraderai Barceló, Josep M. “La formación de un espacio colonial repensada”. Marruecos y el colonialismo español (1859-1912). Eloy Martín Corrales, ed. Barcelona: Bellaterra, 2002. 9-12.

Ghermandi, Gabriella. Regina di fiori e di perle. Roma: Donzelli, 2007.

Glissant, Édouard. Introduction à une poétique du divers. Gallimard, 1996. Poetica del diverso. Francesca Neri, trad. Roma: Meltemi, 1998.

Gnisci, Armando. Creoli meticci migranti clandestini e ribelli. Roma: Meltemi, 1998. Creolizzare l'Europa. Letterature e migrazione. Roma: Meltemi, 2003. Una storia diversa. Roma: Meltemi, 2001.

Karrouch, Laila. De Nador a Vic. Barcelona: Columna, 2004. Inmenso Estrecho. Cuentos sobre la inmigración. Madrid: Kailas, 2005. Inmenso Estrecho II. Cuentos sobre la inmigración. Madrid: Kailas, 2006.

Makaping, Geneviève. Traiettorie di sguardi. E se gli altri foste voi. Soveria Mannelli: Rubettino Editore, 2001.

Mekuy, Guillermina. El llanto de la perra. Barcelona: Plaza Janés, 2005. Las tres vírgenes de Santo Tomás. Madrid: Suma de letras, 2008.

Methnani, Salah y Mario Fortunato. Immigrato. Roma-Napoli: Edizioni Theoria, 1990. Mignolo, Walter D. "Postoccidentalismo: el argumento desde América latina". Teorías sin disciplina (latinoamericanismo, poscolonialidad y globalización en debate). Santiago Castro-Gómez y Eduardo Mendieta, eds. México: Miguel Ángel Porrúa, 1998. 26-49. <http://ensayo.rom.uga.edu/critica/teoria/castro>. 7 julio 2007.

Morón Molina, Virtu; Haik, Kaoutar. La niña de la calle. Una historia real. Barcelona: Styria., 2006.

Naïr, Sami. Y vendrán ... Las migraciones en tiempos hostiles. Barcelona: Planeta, 2006.

Naïr, Sami y Juan Goytisolo. El peaje de la vida. Madrid: Aguilar, 2000.

Nerín Abad, Gustau. Guinea Ecuatorial, historia en blanco y negro. Barcelona: Penínula, 1998.

Nini, Rachid.Diario de un ilegal. Madrid:Ediciones del oriente y del mediterráneo, 2002. Nsue Angüe, María. Ekomo. Madrid: Sial/Casa de África, 2007.

Ponzanesi, Sandra. "Il multiculturalismo italiano". <http://www.sagarana.net/rivista/ numero10/ibridazioni2.html>. 1 feb. 2009.

Paradoxes of Postcolonial Culture: Contemporary Women Writers of the Indian and Afro-Italian Diaspora. Albany: State U of New York P, 2004.

Ponzio, Augusto. “Introduzione". Dall'altro all 'io. Emmanuel Lévinas. Roma: Meltemi editore, 2002. 7-59.

La differenza non indifferente. Comunicazione, migrazione, guerra. Milano: Mimesis, 1995.

Ponzio, Augusto y Susan Petrilli. Il sentire della comunicazione globale. Roma: Meltemi, 2000.

Portelli, Alessandro. "Oltre Babilonia". Il Manifesto. 2 oct. 2008.

Revista Iberoamericana, Vol. LXXX, Núms. 248-249, Julio-Diciembre 2014, 987-1010 
Sabelli, Sonia. "Introduzione alla letteratura italiana della migrazione". <www. casaculture.it/ab/2006/sabelli06.pdf>. 1 feb. 2009.

"Scrittrici eccentriche. Generi e genealogie nella letteratura italiana della migrazione" en Ronchetti, Alessia; Sapegno, Serena (a cura di). Critica feminista e canone letterario negli studi di italianistica. Ravenna: Longo, 2007. 171-9

Said, Edward W. Cultura e Imperialismo. Roma: Gamberetti Editrice, 1998.

Scego, Igiaba. "Dismatria". Pecore nere, racconti. Bari: Laterza, 2006. 5-21 "Identità". Amori bicolori. Bari: Laterza, 2008, 3-33. "Lingua nuova, lingua madre", a cura di. Italiani per vocazione. Fiesole: Cadmo, 2005.

La nomade che amava Alfred Hitchcock. Roma: Sinnos editrice, 2003. Oltre Babilonia. Roma: Donzelli editore, 2008. Rhoda. Roma: Sinnos editrice, 2004.

"Salsicce". Pecore nere, racconti. Bari: Editori Laterza, 2006. 22-36.

Sinopoli, Franca. Bamca Dati Saittori Imnigrati in Lingua Italiano. $<$ http://www.disp. let.uniroma1.it/basili2001>.

Sipi Mayo, Remei. Inmigración y género. El caso de Guinea Ecuatorial. Donostia-San Sebastián: Gakoa Liburuak, 2002.

Mohanty, Chandra Talpade. "Bajo la mirada occidental: la investigación feminista y los discursos coloniales." < http://webs.uvigo.es/pmayobre/master/textos/belen_martin/ investigacion_feminista.RTF.> abril 2009.

Verdicchio, Pasquale. "The Precusion of Postcolonial Discourse in Southern Italy". Revisioning Italy: National Identity and Global Culture. Allen Beverly y Mary Russo, eds. Minneapolis: U of Missesota P, 1997. 191-212.

Revista Iberoamericana, Vol. LXXX, Núms. 248-249, Julio-Diciembre 2014, 987-1010 